\title{
O DIREITO INTERNACIONAL É REALMENTE UMA FORMA DE DIREITO? PODER E SANÇ̃̃̃O NOS MECANISMOS INTERNACIONAIS DE PROTEÇ̃̃̃O AOS DIREITOS HUMANOS
}

\section{INTERNATIONAL LAW IS A TYPE OF RIGHT? POWER AND SANCTION IN INTERNATIONAL HUMAN RIGHTS MECHANISMS}

\author{
${ }^{1}$ Helena Cristina Aguiar De Paula Vilela
}

\section{RESUMO}

Este artigo parte da análise da força coercitiva do direito internacional dos direitos humanos como parâmetro para verificar a juridicidade do próprio direito internacional. Para iniciar esse debate, a pesquisa expôs que há autores que atrelam a noção de direito com o poder de sanção. Sob essa perspectiva, a pesquisa discutiu o enquadramento do direito internacional na noção geral de direito e analisou os mecanismos do sistema interamericano de direitos humanos, para constatar a existência de força coercitiva e sancionatória. Com isso, constatouse que a implementação das normas e decisões pelo Estado atribui poder coercitivo ao direito internacional.

Palavras-chave: Direito internacional, Poder e sanção, Sistema interamericano de direitos humanos

\begin{abstract}
This article analyzed to the coercive force of international law of human rights as a parameter to check the legality of the international law. To start this debate, the research exposed that there are authors which link the notion of right with the power to sanction. From this perspective, discussed the framework of international law in general notion of law and analyzed the inter-American human rights system mechanisms, to establish the existence of coercive and punitive force. Thus, it was found that the implementation of standards and state-decisions is what attaches coercive power to the international law.
\end{abstract}

Keywords/Palabras-claves/Mots-clés: International law, Power and sanction, Interamerican human rights system

\footnotetext{
${ }^{1}$ Mestranda em Ciências Jurídicas da Universidade Federal da Paraíba - UFPB, Paraíba, PB. (Brasil) Delegada de Polícia do Governo do Estado do Rio Grande do Norte -GOVERNO/RN, Rio Grande do Norte, RN. (Brasil). E-mail: helenacris21@ gmail.com
} 


\section{INTRODUÇÃO}

Um dos dilemas atuais do direito internacional dos direitos humanos diz respeito à implementação dos mecanismos de proteção. Para realizar essa implementação, os órgãos contam com a logística dos próprios Estados para promover a execução de suas decisões e, por consequência, a sua efetivação.

Isso se deve ao fato de que, por si só, o direito internacional não possui força coercitiva organizada, ao menos não tão efetiva como o direito interno, capaz de compelir os Estados a respeitarem suas normas. Esse respeito às normas, aliado à prevenção contra violações, constituem objetivos imediatos do direito internacional dos direitos humanos, pois, a tese de que as prescrições jurídicas são feitas para serem descumpridas e, por isso, as condutas sancionadas não é aqui o ideal perseguido.

Neste cenário, o presente artigo analisa a força sancionatória dos mecanismos internacionais de proteção aos direitos humanos como parâmetro para aferição da juridicidade do direito internacional. De fato, alguns autores interpretaram o direito a partir de sua capacidade sancionatória, elemento comum de uma espécie de noção geral do que é direito.

No que diz respeito ao direito internacional, os mecanismos de responsabilização internacional demonstram que há dificuldades no tocante à efetivação de suas decisões. Tal situação é oriunda do escudo da soberania estatal que dificulta não apenas a apuração de eventuais violações, como também, fundamenta a alegação de inexigibilidade das decisões emanadas pelos órgãos internacionais. Por tal razão, questiona-se: o direito internacional, analisado sob o parâmetro dos mecanismos de proteção aos direitos humanos, possui força coercitiva suficiente conforme a acepção de direito como sanção?

Para resolver essa questão, a pesquisa parte da premissa de que as decisões dos órgãos internacionais de proteção têm a efetividade comprometida pela precária força coercitiva que emana. Isso ocorre em razão de o direito internacional ser apoiado nos Estados, os quais, através de seus representantes, figuram como principais legisladores daquele direito. Os Estados, por sua vez, buscam atender aos próprios interesses, muitas vezes ignorando a luta para concretização dos direitos humanos.

Considera-se ainda que, embora haja uma produção jurisprudencial contínua perante os tribunais internacionais, as sanções impostas pela violação às normas previstas nos documentos internacionais não possuem a força vinculante devida. Tal deficiência compromete a proteção dos direitos humanos, na medida em que deixa de inibir violações pela ausência de punição efetiva. 
Portanto, o caminho traçado para desenvolver a pesquisa se iniciou com a discussão acerca da ideia de direito associado à violência, trazida por Benjamin (2013), para, posteriormente, ser verificado se o direito internacional se enquadra em tal conceito. Após do debate dos autores positivistas contemporâneos sobre o tema, como Kelsen (1998), Bobbio (2004; 2014) e Hart (2009), os mecanismos internacionais de proteção aos direitos humanos foram analisados a partir dos meios sancionadores possíveis de utilização. Por fim, o sistema interamericano de direitos humanos, mecanismo de prevenção e responsabilização regional foi estudado, desta vez sob a ótica dos internacionalistas Piovesan $(2007 ; 2008)$ e Trindade (2003), que enxergam a necessidade de reforma do sistema com objetivo de lhe dar efetividade.

Vale ressaltar que, embora se tenha consolidado que os direitos humanos não são exclusivamente direito internacional, tampouco exclusivamente direito interno, a análise da juridicidade do direito internacional tomou, como ponto de partida, o direito internacional dos direitos humanos.

\section{O DIREITO COMO SANÇÃO}

A princípio, a definição do que é o direito não parece complexa, haja vista a existência da noção geral de direito, que o caracteriza por ser emanado por um poder, com caráter prescritivo e com previsão de sanção em caso de descumprimento. Contudo, algumas dificuldades para conceituação surgem no momento em que nem todas as características são identificadas em determinada norma, o que levanta dúvidas a respeito de sua juridicidade.

Essas dificuldades estão relacionadas ao que Hart (2012, p. 4) chama de "casos duvidosos", sobre os quais há "razões, embora em geral não sejam conclusivas, para se negar a exatidão do uso já convencional do termo 'direito' nesses casos”. Nesse sentido, o uso convencional do termo direito, ao qual Hart refere-se, está ligado à noção geral descrita acima, que enumera elementos essenciais para definir se tal norma ou ordenamento são jurídicos.

Para alcançar essa noção geral, são selecionados vários exemplos de direito e, desses exemplos, se extraem características idênticas. Essa suposição, segundo Hart, pode ser dogmática, por isso, ele chama a atenção para os casos duvidosos, como ocorre com o direito internacional. Pois, nada impede que outros exemplos, que possuam apenas algumas das 
características comuns, sejam também abarcados pela definição do direito. A partir de tal noção de direito e dos questionamentos sobre os casos duvidosos, Hart (2012, p. 277) faz a indagação que está expressa neste título: "acaso o direito internacional é realmente uma forma de direito?"

Para Hart (2012, p. 4-5), o problema do direito internacional diz respeito ao seu voluntarismo, isto é, o Estado somente pode ser demandado perante um tribunal internacional com o seu consentimento prévio. Além disso, não há um sistema de sanções eficiente, centralizado e organizado. Contudo, Hart questiona se é possível descaracterizá-lo como direito, em razão da ausência do elemento sanção.

Embora Hart (2012, p. 276) considere a inexistência de um parlamento, de uma jurisdição compulsória e de um sistema organizado de sanções no âmbito internacional, entende que estas não são condições necessárias e suficientes para lhe retirar o status de sistema jurídico. Não há dúvidas de que o direito internacional seja diferente do direito interno e, tomando simplesmente este como parâmetro, a resposta para a pergunta que Hart propôs deverá ser não. Porém, a questão envolve, segundo Hart, a opção de manter o conceito convencional do direito ou dele se afastar.

De fato, Bobbio (2014, p. 145-146) entende que as prescrições jurídicas possuem características que as diferenciam das outras prescrições, sendo uma delas a sanção ${ }^{1}$. Para o autor, as prescrições jurídicas diferem das leis científicas, em razão de definirem o que "deve ser”, por isso, tem, por natureza, a sua própria violação (BOBBIO, 2014, p. 152). Porém, ele admite a incontestável existência de normas sem previsão de sanção. Quando isso ocorre, Bobbio argumenta que o ordenamento jurídico passa a ser entendido em seu conjunto, considerando que a maior parte das normas deve ser sancionada, não necessariamente todas.

Sobre a sanção, outra questão que merece relevância, diz respeito à atribuição da polícia como o braço da sanção no Estado moderno, pois nela está o que institui o direito e que o mantém, ou seja, o "poder violência". A polícia age quando o direito, por si mesmo, não consegue manter a ordem jurídica (BENJAMIN, 2013, p. 69). O poder, portanto, tem duas funções: instituir o Direito e mantê-lo. Nesse sentido, considerando que Benjamin se refere ao "poder-violência", ele questiona se não há outros meios para resolver conflitos de interesses entre humanos que não os violentos.

\footnotetext{
1 Bobbio (2014, p. 153) conceitua sanção como “o expediente através do qual se busca, em um sistema normativo, salvaguardar a lei da eroção das ações contrárias, é, portanto, uma consequência do fato de que em um sistema normativo, diferentemente do que ocorre em um sistema científico, os princípios dominam os fatos, ao invés de os fatos os princípios”.
} 
Benjamin (2013, p. 70) conclui que não é possível solução num contrato jurídico totalmente não violenta, haja vista a presença implícita de uma reação violenta diante da violação do contrato. Para ele, "quando desaparece a consciência da presença latente da violência numa instituição de Direito, esta entra em decadência”. Isso ocorre quando a instituição mostra a ineficácia de suas deliberações pela falta de poder coercitivo.

Embora Benjamin admita que a resolução de conflitos não violenta seja possível, isso ocorre apenas nas relações entre pessoas singulares, as quais renunciam a violência para se utilizarem de meios puros. Contudo, não é a presunção da lei de que os meios puros servem para soluções diretas. A conclusão de Benjamin é que o direito, ao utilizar o poder como violência para atingir um fim, estabelece ligação imediata com a violência. Portanto, o Direito é manifestação da violência.

Sob essa perspectiva, o caráter sancionatório das normas jurídicas mostra-se essencial para sua caracterização como tal. Desse modo, a força coercitiva do direito é apontada por Bobbio e Benjamin como condição para seu êxito. E, nessa ótica, a questão merece debate quando diz respeito às normas do ordenamento internacional, as quais carecem de eficácia reforçada, ao menos não possuem a força coercitiva que detém os Estados.

Sobre a existência ou não de sanção no ordenamento internacional, Kelsen (1998, p. 224-226) enumera duas sanções específicas, as quais também podem assumir a feição de ilícitos: a represália e a guerra. Estas sanções provocam privações da vida, liberdade, propriedade, nos moldes daquelas aplicadas pelo direito estadual. O que as distancia, contudo, do direito estadual, é o fato de que tais normas são direcionadas aos Estados, sujeitos do direito internacional, atingindo, inevitavelmente, o gênero humano.

Kelsen também se debruça sobre a questão do direito internacional como direito. Ele informa que o conceito habitual de direito internacional faz menção a "um complexo de normas que regulam a conduta recíproca dos Estados" (KELSEN, 1998, p. 224). Para ele, somente pode ser direito se compor uma ordem coercitiva da conduta humana, da mesma forma que faz o direito estadual. Então, reconhece o direito internacional como direito, porque possui ordem coercitiva, mesmo que ainda em formação e de grande descentralização.

A análise que Kelsen faz sobre a juridicidade do direito internacional também ressalta a inexistência de um órgão legislativo para produção de normas, além da carência de uma instância para processar juridicamente litígios. Nota-se que, assim como Bobbio, que será mencionado em seguida, Kelsen não considera o sistema da Organização das Nações 
Unidas (ONU) como mecanismo capaz de produzir normas ou de criar instância judicial internacional que possa assumir o caráter obrigatório.

Quanto à Bobbio (2014, p. 169-172), ao associar direito e sanção, entende que o parâmetro utilizado até então era o Estado. Ao partir para o ordenamento internacional, surge o questionamento a respeito da própria juridicidade de tal ordenamento. Contudo, esclarece Bobbio, que constitui ilícito a violação de uma norma de direito internacional, passível de sanções, como represálias e até a guerra, algo regulamentado pelo direito.

Nesses casos, a sanção é aplicada pelo próprio ofendido, ou seja, ocorre a autotutela. Portanto, o ordenamento internacional é regido pelo princípio da autotutela, expressão de uma sociedade menos organizada do que a estatal (BOBBIO, 2014, p. 171-172).

Resta evidente que Bobbio, nesta obra, ignorou a existência de mecanismos coletivos de apuração a violações de direitos, como os tribunais internacionais e os órgãos extrajudiciais de proteção aos direitos humanos. Esses mecanismos representam alternativas para que os Estados não recorram a meios unilaterais de sanção, isto é, não atuem sob o princípio da autotutela.

Sendo assim, o ordenamento internacional, baseado atualmente na existência de tais mecanismos, demonstra através da previsão das sanções externas e institucionalizadas, a juridicidade de suas normas e a eficácia reforçada de suas decisões. Ao mostrar indiferença acerca desses argumentos, Bobbio entendeu que o ordenamento internacional é exemplo de ordenamento sem sanção.

Sob a perspectiva dos direitos humanos, contudo, Bobbio (2004, p. 22-23) sustentou que, com o advento da Declaração Universal dos Direitos Humanos de 1948, o problema do fundamento desses direitos estava solucionado. Para ele, a partir da Declaração, chegou-se à certeza histórica de que a humanidade partilhava valores comuns (BOBBIO, 2004, p. 26). A preocupação, portanto, passou a ser de que modo garantir esses direitos.

No entanto, Feitosa (2013, p. 86-87) entende que Bobbio incidiu numa grande imprecisão ao tratar dos direitos humanos, pois ao tempo em que buscou fundamentação histórica dos direitos humanos, afirmou seu caráter universal, algo, para ele, paradoxal. E não apenas isso, pois Bobbio defendeu que a Declaração Universal também inaugurou a afirmação positiva dos direitos humanos, que deverão ser "efetivamente protegidos até mesmo contra o próprio Estado que os tenha violado" (BOBBIO, 2004, p. 30).

Mas, de que forma garantir a efetividade desses direitos, tendo em vista que não são dotados de força coercitiva e fazem parte de um ordenamento sem sanção? Bobbio (2004, p. 
31) visualiza essa dificuldade em programar medidas eficientes num ordenamento que não detém o monopólio da força, que caracteriza o Estado moderno. Para ele, a comunidade internacional não se encontrava em condições de fornecer garantias válidas para os direitos humanos.

De fato, Sorto (2013, p. 356) observa que embora Bobbio tenha encontrado no cenário internacional, as Nações Unidas, à época de sua obra "O terceiro ausente: ensaios e discursos sobre a paz e a guerra", continuou defendendo a ausência desse "terceiro", que representaria o organismo para paz. Isso reforça o argumento de que Bobbio, efetivamente, ignorou a presença do mecanismo coletivo existente, qual seja, os órgãos das Nações Unidas.

Justificando a postura de Bobbio, Sorto (2013, p. 356) afirma que as Nações Unidas não são eficazes no papel de "terceiro", pois não são capazes de dirimir os conflitos internacionais, a exemplo do ataque dos Estados Unidos ao Iraque, que utilizou a reação unilateral em resposta ao atentado de 11 de setembro. Sorto conclui que não apenas Bobbio, como o próprio Kant diriam, diante da atual realidade, que o direito internacional contemporâneo é inoperante na manutenção da paz, enquanto não ocorrer mudanças no âmbito das Nações Unidas, notadamente no Conselho de Segurança (SORTO, 2013, p. 357$358)$.

Essa também corresponde à crítica de Hart, para quem a Carta da ONU não criou sanções sequer equiparáveis às do direito interno. Segundo ele, "todas as vezes que seu uso [sanção] for importante, as cláusulas jurídicas vinculantes da Carta serão paralisadas pelo veto, devendo-se dizer que existem apenas no papel” (HART, 2012, p. 280). Demonstra, portanto, o caráter político que as normas do direito internacional assumem, com mais influência sobre as decisões do que qualquer teor jurídico.

$\mathrm{Na}$ verdade, Hart (2012, p. 283), ao distinguir o direito internacional do direito interno, argumenta que, ao contrário do direito interno, nas questões internacionais, as sanções devem ser evitadas. Tendo em vista que as violações de normas ocorrem entre Estados, é indicado que não haja sanções que levem à represálias e guerras, pois trariam malefícios para todos os envolvidos e não somente para o Estado infrator.

Contudo, algumas questões devem ser esclarecidas. Primeiramente, sustentar que a Organização das Nações Unidas não é eficaz no papel de manutenção da paz não implica que seus mecanismos coletivos de proteção efetivamente não estejam à disposição para tal fim. Pois, compõem a ONU, órgãos com atribuições de expedir recomendações e relatórios, exigindo o cumprimento de obrigações assumidas pelos Estados, além do órgão judicial global mais importante, que é a Corte Internacional de Justiça², todos a serviço da proteção à 
pessoa humana.

Obviamente que, se comparadas às normas de direito interno, o direito internacional carece de normas suficientemente vinculantes. Mas, essas normas servem para deslegitimar atos, como no caso citado acima do ataque norte-americano ao Iraque, sem a autorização do Conselho de Segurança. Também, são normas invocadas na proteção dos direitos humanos, que possuem caráter transnacional, para não se sujeitarem exclusivamente à apreciação dos Estados soberanos.

Além disso, ao defender que normas de direito internacional envolvem unicamente relações entre Estados e, por isso, a eventual violação não carece da sanção da mesma forma que o direito interno, ignoram as violações de direitos humanos. Quando tais violações ocorrem, os indivíduos são atingidos diretamente. Além de esses casos afetarem toda a comunidade internacional, os povos são as maiores vítimas do descumprimento das normas.

Com relação às sanções citadas pelos autores, isto é, represálias e guerras, há de se ressaltar, como se verá adiante, que os mecanismos coletivos de responsabilização dos Estados preveem outras formas de sanção. Dentre elas, é possível citar o rompimento das relações diplomáticas, mencionado na Carta da ONU (Artigo 41), e a indenização compensatória para a vítima, que tem previsão na Convenção Americana de Direitos Humanos (Artigo 68 (2)).

Portanto, para análise da juridicidade do direito internacional, é preciso conhecer os mecanismos atualmente disponíveis e verificar se eles poderão assumir uma eficácia reforçada. Ou o contrário, isto é, esses mecanismos poderão estar fadados à decadência, pela ausência do poder-violência que institui e mantém o direito.

2 É importante consignar que a Corte Internacional de Justiça não é um tribunal de direitos humanos. Nesse sentido, Alston (2014) critica a ansiedade de alguns estudiosos e da própria ONU por uma corte mundial de direitos humanos, pois, além de mascarar problemas mais urgentes, não seria a hora para colocar tantos poderes nas mãos de poucos juízes. Ao se referir a esta proposta de corte mundial, o autor discorre sobre como seria seu relacionamento com outros órgãos, como a Corte Internacional de Justiça. 


\section{SISTEMA DE SANÇÕES DOS MECANISMOS INTERNACIONAIS DE PROTEÇÃO AOS DIREITOS HUMANOS}

A responsabilização de todos os Estados, independentemente de ratificação de tratados, por violações a normas internacionais, ainda é um sonho distante. Isso porque ainda domina o entendimento de que os Estados soberanos são livres para decidir fazer parte ou não de um sistema que contenha mecanismos de responsabilização. Além disso, os mecanismos existentes sofrem críticas constantes pela falta de efetividade e pela ausência de força coercitiva.

Antes de mencionar alguns órgãos que compõe os mecanismos internacionais de responsabilização, é importante distinguir os mecanismos coletivos dos unilaterais. Estes correspondem aos mencionados por Kelsen e Bobbio, referenciados no tópico anterior, isto é, são aqueles que o Estado ofendido exige diretamente do Estado agressor reparação, sob pena de sanção equivalente à represália e até à guerra.

No mecanismo unilateral, o Estado ofendido exige reparação por parte do Estado agressor que, por sua vez, não aceita a decisão do primeiro. A partir disso, é dado início à escalada de sanções que não conduz a uma solução pacífica (RAMOS, 2012, p. 33). Outra vez, retoma-se o exemplo da política externa dos Estados Unidos, que se utiliza de mecanismo unilateral de responsabilização, ignorando os pareceres dos órgãos da ONU.

No tocante aos mecanismos coletivos, são aqueles compostos por órgãos extrajudiciais e judiciais, criados a partir de tratado específico. Nesses mecanismos, o processo de apuração da responsabilidade ocorre perante órgãos imparciais, sujeitando o Estado infrator à sanção previamente determinada (RAMOS, 2012, p. 33).

Dentre esses mecanismos coletivos, destacam-se os órgãos criados por tratados internacionais. Vale ressaltar que os tratados de direitos humanos não possuem caráter sinalagmático, diferentemente daqueles que preveem vantagens mútuas para os contratantes. Isso significa que o descumprimento de norma presente no tratado de direitos humanos não implica em extinção do tratado ou que os demais contratantes poderão igualmente descumprir tal norma.

Vige, portanto, o chamado "regime objetivo das normas de direitos humanos" (RAMOS, 2012, p. 40). Como consequência, o regime objetivo reflete o tratamento diferenciado com relação às normas de direitos humanos, que se distanciam do caráter 
bilateral dos tratados tradicionais. Também submetem os infratores ao regime de sanção coletiva, pois afetam não só o Estado-vítima, mas todos os Estados, uma vez que há normas essenciais previstas em tratados de direitos humanos inderrogáveis, que constituem interesse de toda a comunidade internacional (RAMOS, 2012 p. 40-42). Tais normas essenciais podem ser estendidas mesmo a Estado não contratante de determinada Convenção ${ }^{3}$.

Contudo, em vez de avançar nesse sentido, a Corte Internacional de Justiça, no caso Timor Leste (INTERNATIONAL, 1991), entendeu que não poderia julgar a conduta de Estado que não fosse parte da demanda e que não reconhecesse sua jurisdição ${ }^{4}$. Nesse ponto, a Corte recuou ao atrelar sua jurisdição ao reconhecimento, independentemente de a questão envolver normas de direitos humanos. Embora seja a Corte que mais se aproxima do tribunal com jurisdição mundial, o seu caráter não obrigatório compromete a efetividade da justiça e do próprio direito internacional.

Cumpre esclarecer que os direitos humanos não equivalem necessariamente ao direito internacional, assim como não estão contidos exclusivamente no direito interno. Alguns autores, como Zumbansen (2012), posicionam os direitos humanos como direito transnacional, ou seja, que ultrapassam as fronteiras do Estado, sendo que a construção desses espaços envolve a atividade humana, comunicação e racionalidade.

Por isso, a análise a efetividade dos mecanismos internacionais de proteção aos direitos humanos, realizada na presente pesquisa, corresponde à vertente do chamado direito internacional dos direitos humanos. Essa vertente pode ser conceituada como "o direito que está relacionado com a proteção dos indivíduos e dos grupos contra as violações de seus direitos internacionalmente garantidos, e com a promoção destes direitos [tradução do autor]" (BUERGENTHAL, SHELTON e STEWART, 2009, p. 1).

Sob tal ótica, a força coercitiva das decisões dos órgãos e a justiciabilidade dos direitos humanos foram verificadas. Contudo, não se deve esquecer que tal questão demanda estudo mais complexo, com a análise dos sistemas judiciais e das políticas públicas dos ordenamentos internos.

\footnotetext{
3 Não obstante os Estados Unidos não terem ratificado a Convenção Americana de Direitos Humanos, são membro da Organização dos Estados Americanos, que tem como principal órgão (mecanismo coletivo) a Comissão Interamericana de Direitos Humanos, com atribuição para processar o referido Estado, com base na Declaração Americana de Direitos do Homem e em normas cogentes do direito internacional.

${ }^{4}$ No julgamento do caso Timor Leste, a Corte Internacional de Justiça decidiu: "26. The Court recalls in this respect that one of the fundamental principles of its Statute is that it cannot decide a dispute between States without the consent of those States to its jurisdiction" (INTERNACIONAL, 1991, parágrafo 26).
} 
Não apenas a falta do foro jurisdicional obrigatório embarga a efetividade dos mecanismos de responsabilização dos Estados. A situação se agrava no momento em que se faz necessário recorrer à sanções internacionais coletivas, no caso de descumprimento de obrigações por parte dos Estados que ratificaram os tratados e reconheceram a jurisdição do Tribunal ou órgão. Basta analisar os mecanismos de responsabilização da ONU, as sanções previstas e sua aplicabilidade.

De fato, a ONU aparece como o mais desenvolvido mecanismo coletivo, voltado ao tema direitos humanos. Um dos seus órgãos, o Conselho de Segurança, pode fazer-se valer de sanções econômicas ou mesmo intervir por meio da força, nos casos de grave comoção (GALINDO, 2010, p. 184-185). Contudo, o Conselho de Segurança é composto por cinco potências mundiais com poder de veto, as quais, além de não se mostrarem capazes de representar a comunidade internacional (RAMOS, 2012, p. 127-128), são as mais interessadas na não interferência da ONU em seus assuntos com outros Estados.

Dentre as medidas que poderão ser tomadas pelo Conselho de Segurança, para fazer valer suas decisões, a Carta da ONU de 1945 enumera, no Artigo 41, as seguintes: "a interrupção completa ou parcial das relações econômicas, dos meios de comunicação ferroviários, marítimos, aéreos, postais, telegráficos, radiofônicos, ou de outra qualquer espécie e o rompimento das relações diplomáticas". Esse dispositivo não compõe um rol exaustivo, pois, por meio de resoluções, o Conselho de Segurança pode aplicar outro tipo de embargo.

Estas medidas, que não envolvem o emprego de força, poderão ser tomadas para tornarem efetivas suas decisões. O Conselho convidará, ainda, os Estados membros da ONU para aplicarem as medidas (CARTA, 2015, art. 41). Embora caiba ao Conselho de Segurança, inclusive tomar medidas armadas para manter e estabelecer a paz, não dispõe uma polícia internacional específica. A força militar à disposição do Conselho é composta pelos exércitos dos Estados, conforme Artigo 43 da Carta da ONU.

Depreende-se da estruturação do Conselho de Segurança, com a força vinculante de suas decisões, que tem aparato suficiente à disposição para aplicar as sanções previstas. Contudo, como ressalta Ramos (2012, p. 152), o que leva a falta de efetividade do Conselho

\footnotetext{
${ }^{5}$ No original: "the law concerned with the protection of individuals and groups against violations of their internationally guaranteed rights, and with the promotion of these rights".
} 
de Segurança é o "imobilismo e indiferença, motivadas pelos interesses geopolíticos dos cinco detentores do poder de veto". Por razões evidentes: os membros permanentes do Conselho protagonizam violações e, além disso, utilizam-se do órgão para cometer arbitrariedades, a exemplo das intervenções sob o pretexto de humanizar.

Corroborando tal visão, Douzinas (2009, p. 131) menciona a precariedade dos mecanismos internacionais, os quais possuem como meio principal de sanção a publicidade negativa e a consequente possibilidade de causar vexame ao Estado violador. Verifica-se, portanto, a debilidade dos mecanismos que garante o fortalecimento da soberania dos Estados.

Sob essa visão, Douzinas elabora uma crítica direcionada aos problemas de efetividade das leis internacionais dos direitos humanos. Ele ilustra seu pensamento fazendo referência ao mecanismo internacional mais bem sucedido, em sua opinião, qual seja, a Convenção Europeia de Direitos Humanos de 1950. Tal sistema europeu, até o ano de 1998, admitia que o Comitê de Ministros resolvesse questões, as quais não cabiam ser submetidas à Corte, que acabavam sendo deixadas em suspenso. Além disso, a pessoa que reivindicava direitos perante seus órgãos não tinha acesso direito ao Tribunal (DOUZINAS, 2009, p. 131).

Em 1998, não obstante, mudanças foram promovidas no sistema europeu, fundindo a Comissão Europeia e o Tribunal existente em um só órgão, a Corte Permanente de Direitos Humanos, além de ter extinguido o Comitê de Ministros. Embora a situação narrada por Douzinas tenha se alterado com o Protocolo n ${ }^{\circ} 11$ de 1998, outro problema persiste. Trata-se da nomeação dos membros da Corte pelos Estados-parte, os quais, segundo Douzinas (Idem, p. 131), ficam atrelados aos interesses daqueles que os nomearam.

Sobre o assunto, Douzinas (2009, p. 132) é categórico: "pesquisar as filiações políticas dos juízes nomeados pelos governos é uma preparação melhor do que estudar as leis elaboradas a partir de casos precedentes do Tribunal". Refere-se Douzinas ao Tribunal Europeu de Direitos Humanos, o único, segundo ele, que possui precedentes judiciais desenvolvidos. Esses fatores comprometem a legitimidade dos mecanismos, o que, por consequência, atinge a efetividade.

$\mathrm{Na}$ análise do Sistema Interamericano, a questão da responsabilização dos Estados encontra outras barreiras. Com relação ao mecanismo americano, os órgãos que o compõem são a Comissão Interamericana de Direitos Humanos (CIDH), também principal órgão da Organização dos Estados Americanos (OEA), e a Corte Interamericana de Direitos Humanos (Corte IDH). A Corte é acionada apenas pela citada Comissão e pelos Estados-parte. Diante de uma violação a direitos, cabe à Comissão fazer tramitar o procedimento, muitas vezes 
$\operatorname{moroso}^{6}$ para, ao final, sujeitar a demanda à Corte, caso o Estado demandado reconheça sua jurisdição. Do contrário, a Comissão emitirá um "Informe" que tem o caráter vinculante questionável.

Sobre a força vinculante dos informes da Comissão, a Corte entendeu, baseada no princípio da boa fé nos Tratados, que devem ser cumpridos, notadamente o Segundo Informe, elaborado na hipótese em que o Estado infrator não reconhece a jurisdição da Corte ${ }^{7}$. Contudo, quando o Estado descumpre as recomendações contidas no Segundo Informe, cabe à Comissão encaminhar relatório informando o descumprimento à Assembleia Geral da OEA. Em posse de tal informação, a Assembleia notifica o Estado para cumprir as deliberações da Comissão, contando, depois, com o arquivamento do relatório.

Nota-se, portanto, que os mecanismos de responsabilização, com atribuição para estabelecer sanções, carecem de força coercitiva, se comparados aos Estados. Mesmo o sistema europeu de direitos humanos, mais antigo e com jurisprudência consolidada, é alvo de críticas no que concerne à sua efetividade. Com relação ao sistema interamericano, os internacionalistas propõem reformas que visam dotar o mecanismo coletivo de legitimidade na atuação contra violações aos direitos humanos.

Além disso, certas peculiaridades caracterizam o sistema interamericano e o diferenciam do europeu, desde sua origem. Aquele sistema merece atenção, em razão das propostas de reforma sistemática que correspondem à bandeira defendida pelos ex juízes da Corte interamericana e de alguns internacionalistas brasileiros, como Cançado Trindade e Piovesan. Tal reforma visa vencer os problemas de efetividade e de juridicidade da Corte Interamericana de Direitos Humanos.

\footnotetext{
${ }^{6}$ No caso Gomes Lund, a Comissão recebeu a petição contendo a denúncia do fato em 1995. O processo tramitou na Comissão e, graças à insistência dos peticionários, treze anos após ter ciência da Guerrilha do Araguaia, a Comissão elaborou o relatório de mérito, no ano 2008 (Caso no 11.552, Brasil, 2009).

${ }^{7}$ No caso Loayza Tamayo Vs. Peru (1997), a Corte Interamericana de Direitos Humanos entendeu (80-81): "Sin embargo, en virtud del principio de buena fe, consagrado en el mismo articulo 31.1 de la Convencion de Viena, si un Estado suscribe y ratifica un tratado internacional, especialmente si trata de derechos humanos, como es el caso de la Convencion Americana, tiene la obligacion de realizar sus mejores esfuerzos para aplicar las recomendaciones de un organo de proteccion como la Comision Interamericana (...) por lo que, al ratificar dicha Convencion, los Estados Partes se comprometen a atender las recomendaciones que la Comision aprueba en sus informes."
} 


\section{AS PECULIARIDADES DO SISTEMA INTERAMERICANO DE DIREITOS HUMANOS: por um sistema justiciável}

"O grande desafio do Direito Internacional sempre foi o de adquirir "garras e dentes", ou seja, poder e capacidade sancionatória" (PIOVESAN, 2008, p. 30-31). Em busca de tal capacidade, alguns internacionalistas se dedicaram a apresentar propostas para reforma do sistema interamericano de direitos humanos, com vistas a efetividade e justiciabilidade do mecanismo coletivo de proteção.

Não é simples tarefa avaliar a efetividade de um tribunal de direitos humanos, pois não envolve tão somente a quantificação dos casos que resolve ${ }^{8}$. De fato, a efetividade é medida pelo sucesso em incentivar a adesão pelos Estados às normas estabelecidas na Convenção, além de verificar que os Estados criaram mecanismos de prevenção a violações (SHAVER, 2010, p. 665). Por isso, dentre as propostas de reforma, é possível identificar a implementação de mecanismos sancionatórios e reparadores pelos próprios Estados.

Porém, antes de elencar as propostas, importa situar o sistema regional interamericano desde sua origem, bem como as disparidades e semelhanças com o sistema que o inspirou, o europeu. Pois, a questão que surge é: como uma região pioneira em declarar direitos do homem obteve o êxito de criar um sistema convencional em meio a ditaduras militares na maioria de seus Estados?

Em busca da resposta de tal indagação, pode-se considerar a constatação de Shaver (2010, p. 642):

Por sua vez, a Comissão Interamericana de Direitos Humanos foi criada em 1959, assumindo o objetivo promover os direitos consagrados na Declaração Americana de 1948. Posteriormente, através do Protocolo de Buenos Aires de 1967, a Comissão foi autorizada a receber e examinar petições individuais com notícias de violações, inquirir Estados e recomendar condutas (OEA, 2015). Esse Protocolo deu maior autonomia à Comissão Interamericana no bloco de órgãos da OEA, que passou a ter a atribuição de emitir recomendações aos Estados. O não cumprimento dessas recomendações é informado à Assembleia Geral da OEA, a quem cabe aplicar as sanções pertinentes.

\footnotetext{
${ }^{8}$ No ano de 2014, foram 1758 petições recebidas pela Comissão Interamericana de Direitos Humanos, contra apenas 19 casos enviados à Corte e 6 informes de solução amistosa (COMISIÓN, 2015).
} 
Apesar de ter sido aprovada em 1969, a Convenção Americana apenas entrou em vigor internacionalmente em 1978, com a ratificação do $11^{\circ}$ Estado, mínimo exigido de ratificações. O Brasil, por exemplo, somente ratificou a Convenção em 1992 e apenas reconheceu os mecanismos de fiscalização, como o da Corte Interamericana, em 1998 (OEA, 2015).

Ainda assim, o sistema prosperou e, apesar de nem sempre os Estados cumprirem as recomendações e as decisões da Corte e da Comissão, para Shaver (2010, p. 667), a simples

ameaça de intervenção e sanções reputacionais refletem positivamente na conformidade dos Estados com as normas de direitos humanos. Contudo, o sistema interamericano ainda sofre limitações e carece de reformas.

As mudanças necessárias, no entendimento de Trindade (2003, p. 80-81), não são atinentes ao núcleo dos direitos protegidos. Referem-se, no entanto, aos mecanismos e aos procedimentos perante os órgãos do sistema interamericano. A seu juízo, a questão mais urgente consiste na viabilização da efetiva participação das vítimas nesses procedimentos (TRINDADE, 2003, p. 81).

Nessa perspectiva, as propostas apresentadas por Piovesan (2007, p. 129) ambicionam, primeiramente, a democratização do sistema interamericano, a partir do acesso direto à Corte pelos indivíduos e pelas organizações não governamentais, imprimindo "o protagonismo da sociedade civil" na esfera interamericana. Outra proposta de mudança diz respeito aos membros da Comissão Interamericana e da Corte, os quais devem ser dotados de independência, com critérios mais objetivos de indicação para o cargo e menos ligados aos interesses governamentais (PIOVESAN, 2007, p. 129).

Existe, ainda, a necessidade de estabelecer jurisdição obrigatória da Corte, substituindo, portanto, a exigência de reconhecimento expresso, como condição para processamento de demandas, pelo automatismo dos Estados-parte da Convenção (PIOVESAN, 2007, p. 129; TRINDADE, 2003, p. 93). Essa terceira proposta representa a superação de uma das críticas à juridicidade do direito internacional, diante da persistente voluntariedade dos Estados em reconhecer a jurisdição dos tribunais internacionais.

\footnotetext{
${ }^{9}$ No original: Although there were relatively few democracies in the Western Hemisphere during the first half of the twentieth century, intellectual leaders in the American region shared a common heritage of philosophical agreement on human rights, stemming from the Enlightenment.
} 
A alteração da Convenção nesse sentido provocaria uma revolução, no tocante ao acesso à justiça internacional ${ }^{10}$.

Outras propostas são levantadas por Piovesan, visando dar efetividade ao sistema, tais como a criação de mecanismos de supervisão do cumprimento das decisões, além de medidas logísticas para independência técnica e financeira dos órgãos do sistema interamericano (PIOVESAN, 2007, p. 129-130). O monitoramento, portanto, deve ser realizado pelos órgãos da OEA de forma contínua, verificando a execução pelos Estados das decisões tomadas pela Corte.

Contudo, a proposta de relevância para justiciabilidade do mecanismo analisado refere-se à "exigibilidade de cumprimento das decisões internacionais no âmbito interno, com a adoção, pelos Estados, de legislação relativa à implementação das decisões internacionais em matéria de direitos humanos" (PIOVESAN, 2007, p. 130). Sobre essa proposta específica, a autora faz breve levantamento entre os países latino-americanos, com a finalidade de verificar como estes contribuem para a implementação das decisões da Corte Interamericana $^{11}$.

O resultado desse levantamento aponta que o Peru foi pioneiro ao conferir validação automática às resoluções dos organismos internacionais. Da mesma forma, Honduras obrigouse a cumprir as decisões desses organismos, assim como a Venezuela e a Colômbia. Por sua vez, a Costa Rica assinou um acordo com a Corte Interamericana, comprometendo-se a equiparar as decisões tomadas por ela àquelas proferidas pelo Poder Judiciário nacional, inclusive, prevendo dotação orçamentária específica voltada ao cumprimento das decisões (PIOVESAN, 2008, p. 33).

Nesse sentido, observa Trindade (2003, p. 84), "no âmbito da OEA, já se firmou o consenso no sentido de que os Estados-partes na Convenção Americana são efetiva e conjuntamente os 'garantes' da integridade da mesma" (tradução do autor) ${ }^{12}$. Como dito, os

\footnotetext{
10 Atualmente, vale dizer, dos 25 (vinte e cinco) Estados signatários da Convenção, 22 (vinte e dois) Estados reconhecem expressamente a jurisdição da Corte (COMISSÃ̃, 2007). Isso corresponde a $88 \%$ dos Estados que fazem parte do sistema convencional. Contudo, mesmo verificando tal maioria, o reconhecimento obrigatório conferiria maior seriedade ao sistema regional. Ou melhor, se os Estados membros da OEA fossem vinculados automaticamente à Convenção e, por consequência, à Corte.

${ }^{11}$ Em atendimento à exigência do Artigo 28, item 2, da Convenção Americana, os Estados assumem a obrigação de implementar medidas para que a Convenção seja efetivamente cumprida.

${ }^{12}$ No original: (...) en el ambito de la OEA, ya se formo el consenso en el sentido de que los Estados Partes en la Convencion Americana son efectiva y conjuntamente los garantes de la integridad de la misma.
} 
Estados se comprometem a cumprir os termos do Tratado, e mais ainda, reconhecem expressamente a jurisdição da Corte. Caso deixem de executar as decisões desta, os Estados estarão violando a Convenção pela segunda vez. Além disso, não é idôneo alegar dificuldades na ordem interna para se furtar de cumprir as obrigações (TRINDADE, 2003, p. 84-85).

A proposta oferecida pelo autor concerne em introduzir um adendo à Convenção, para compelir os Estados a adotar procedimento interno de execução da sentença dos tribunais internacionais, sobretudo do sistema regional interamericano. O texto deveria estar expresso, segundo sugere Trindade (2003, p. 85), da seguinte forma: "Em caso de dito procedimento interno ainda não exista, os Estados partes se comprometem a estabelecê-lo, em conformidade com as obrigações gerais estipuladas nos artigos 1 (1) e 2 desta Convenção" (tradução do autor $^{13}$. Os dispositivos da Convenção citados falam sobre o compromisso dos Estados partes em respeitar os direitos e liberdades nela previstos, além de criar medidas legislativas ou de outra natureza para tornar efetivo tal compromisso.

Por fim, outra proposta sustentada é de que a Convenção Americana não deveria admitir reserva (TRINDADE, 2003, p. 86-87). Embora a Convenção de Viena sobre o Direito dos Tratados de 1969 preveja tal possibilidade, a Convenção de direitos humanos, por essa especificidade, não deveria permitir que os Estados pudessem fazer reservas a seu texto. Os Estados, portanto, adotariam o texto da Convenção em sua integralidade.

Porém, tão importante quanto a proibição de reserva, para os fins de garantir a efetividade e a coercibilidade das decisões da Corte, é a proibição da denúncia. Uma vez que se torna conveniente ao Estado não fazer mais parte do sistema, diante de decisões condenatórias e com previsão de duras sanções, denuncia a Convenção e se desliga de qualquer compromisso com aquele sistema.

Tal meio de fuga à responsabilização foi utilizado pela Venezuela, ao denunciar a Convenção Americana ${ }^{14}$, quando vivia o auge do governo Chavez, em 2012, com decisão confirmada por Maduro, um ano após. Embora a Convenção (Artigo 78) disponha que a denúncia não tem efeito de isentar os Estados das obrigações por atos cometidos anteriormente, o Estado deixa de se submeter à Corte Interamericana, prevista unicamente no sistema convencional.

\footnotetext{
13 Conforme o original: "En caso de que dicho procedimiento interno todavia no exista, los Estados Partes se comprometen a establecerlo, en conformidad con las obligaciones generales estipuladas en los articulos 1(1) y 2 de esta Convencion".

14 "En el día de hoy, el gobierno de la República Bolivariana de Venezuela comunicó al Secretario General de la Organización de los Estados Americanos, José Miguel Insulza, mediante nota oficial, que denuncia la Convención Americana sobre Derechos Humanos" (ORGANIZACIÓN, 2012)
} 
Obviamente que a denúncia ao tratado está relacionada à noção de voluntarismo, ou seja, os Estados, por questão de soberania, não são obrigados a ratificar, como também a permanecer como membro do tratado (VARELLA, 2012, p. 36). Há o risco, inclusive, de o tratado ser modificado de tal maneira que se torne contrário à política do Estado, e este recorrerá à denúncia (Idem, p. 87).

Contudo, conforme Varella (2012, p. 171), alguns tratados não admitem denúncia, como aqueles que preveem normas imperativas (jus cogens), como a Carta da ONU, além de tratados de paz ou que estabelecem limites territoriais entre os Estados, como a Convenção Internacional sobre o Direito do Mar. Nesse raciocínio, a Convenção Americana de Direitos Humanos não deveria aceitar denúncias para não retirar da população regional o instrumento da Corte que é, por muitas vezes, a única esperança de responsabilizar Estados violadores dos direitos humanos.

É possível depreender de tais propostas que a dificuldade em garantir a eficácia dos direitos humanos está na debilidade dos mecanismos de proteção. Para alcançar efetividade, precisam se apoiar nos Estados, cujo papel reside em implementar os mecanismos no âmbito interno.

Isso significa que, na ausência de força dos mecanismos internacionais de proteção aos direitos humanos, a solução é buscar essa força nos próprios Estados. Estes detém o monopólio da força no âmbito interno, incorporam tratados internacionais em seu ordenamento e introduzem normas internacionais em suas constituições. Além disso, através de atos e poderes, implementam os mecanismos de proteção para efetivar as decisões e recomendações dos órgãos internacionais.

Contudo, é importante destacar, que os Estados figuram, na maioria das vezes, como réus nas demandas, ou seja, são apontados como principais agentes violadores dos direitos das pessoas. Por mais que visem proteger seu povo e os residentes em seu país, vão se afastar do discurso irrestrito dos direitos humanos no momento em que for alvo de uma imputação.

\section{CONCLUSÃO}


O estudo do direito internacional sob a perspectiva da sanção demonstrou o quanto a ausência dessa força pode comprometer sua juridicidade. Por outro lado, no que tange à questão dos direitos humanos, a carência de força vinculante e de capacidade sancionatória/ reparadora retira dos mecanismos de proteção a efetividade necessária em responsabilizar Estados violadores e evitar que tais violações se tornem recorrentes.

É válido ressaltar que as sanções esperadas, no tocante à violação de normas internacionais de direitos humanos, se distanciam da ideia de represália e da guerra. Estas sanções, muitas vezes, reforçam as violações, que atingem não somente o Estado infrator, mas a população civil. Nessa perspectiva, a indenização às vítimas até o rompimento de relações diplomáticas, ou seja, as sanções sem uso da força são as mais indicadas para lidar com o problema do descumprimento das normas de direitos humanos.

Foi possível verificar, ainda, que a força coercitiva do direito internacional se apoia no direito dos Estados. Tal constatação restou evidente na análise das propostas de reforma do sistema interamericano, as quais focalizam, em sua maioria, na atuação mais efetiva por parte dos Estados, com o intuito de reforçar seu compromisso. Sob esse ponto de vista, o poder coercitivo do direito internacional depende diretamente da implementação de mecanismos e procedimentos por parte do Estado.

Portanto, para alcançar a efetividade dos órgãos internacionais de direitos humanos, judiciais ou não, é necessário que os Estados assumam seu papel no combate às violações. Devem, então, cooperar com os sistemas regionais e globais de responsabilização para assegurar que as decisões sejam cumpridas com a utilização da força que detém.

\section{REFERÊNCIAS}

ALSTON, P. Against a world court for human rights. Ethics and internacional affairs. 2014. New York University School of Law. Disponível em http://ssrn.com/abstract=2344333. Acesso em 14 Set 2015.

BENJAMIN, W. Sobre a crítica do poder como violência. In: $O$ anjo da história. $2^{\mathrm{a}}$ ed. Belo Horizonte: Autêntica Editora, 2013.

BOBBIO, N. A era dos direitos. Rio de Janeiro: Elsevier, 2004.

Teoria da norma jurídica. $5^{\mathrm{a}}$ ed. São Paulo: EDIPRO, 2014. 
BUERGENTHAL, T.; SHELTON, D.; STEWART, D. P. International human rights in a nutshell. $4^{\text {th }}$ edition. Saint Paul: West, 2009.

CARTA das Nações Unidas. ONUBR Nações Unidas no Brasil Disponível em http://nacoesunidas.org/carta/ Acesso em 27 Ago 2015.

COMISIÓN Interamericana de Derechos Humanos. Estadísticas. Disponível em http://www.oas.org/es/cidh/multimedia/estadisticas/estadisticas.html. Acesso em 10 Set 2015.

COMISSÃO Interamericana de Direitos Humanos. Documentos básicos em matéria de direitos humanos do sistema interamericano. 31 janeiro de 2007. Disponível em http://www.cidh.oas.org/basicos/portugues/TOC.Port.htm. Acesso em 10 Set 2015.

CORTE Interamericana de Derechos Humanos. Casos contenciosos. Disponível em http://www.corteidh.or.cr/cf/Jurisprudencia2/busqueda_casos_contenciosos.cfm?lang=es.

Acesso em 02 Set 2015.

DOUZINAS, Costa. O triunfo da humanidade: de 1789 a 1989 e dos direitos naturais aos direitos humanos. In: O fim dos direitos humanos. São Leopoldo: Editora Unisino, 2009.

FEITOSA, E. Bobbio e a crítica de Marx aos direitos humanos: o que e quais são os direitos humanos? Elementos para uma refutação da concepção individualista dos direitos humanos. In: TOSI, G. (org). Noberto Bobbio: democracia, direitos humanos, guerra e paz. João Pessoa, Editora da UFPB, 2013.

GALINDO, G. R. B. Instituições e procedimentos. IN: PETERKE, S. (Coord) Manual prático de direitos humanos internacionais. Brasília: ESMPU, 2009.

HART, H. L. A. O conceito de direito. São Paulo: Editora WMF Martins Fontes, 2009.

INTERNATIONAL Court of Justice. Cases. East Timor (Portugal v. Australia). 22 february 1991. Disponível em http://www.icj-cij.org/docket/index.php?p1=3\&p2=3 Acesso em 14 Set 2015.

KELSEN, H. Teoria pura do direito. $6^{\text {a }}$ ed. São Paulo: Martins Fontes, 1998.

ORGANIZACIÓN de los Estados Americanos. Comunicado de prensa. Secretario General de la OEA comunica denuncia de la Convención Americana sobre Derechos Humanos de parte de Venezuela. 10 de septiembre de 2012. Disponível em http://www.oas.org/es/centro_noticias/comunicado_prensa.asp?sCodigo=C-307\%2F12. Acesso em 14 Set 2015.

. Breve historia del sistema interamericano de derechos humanos. Disponível em http://www.oas.org/es/cidh/mandato/que.asp. Acesso em 14 Set 2015.

PIOVESAN, F. Brasil e o sistema interamericano de proteção dos direitos humanos: impacto, desafios e perspectivas. Anuário Brasileiro de Direito Internacional. n. II-2, junho, 2007. Disponível em http://international.vlex.com/vid/interamericano-direitos-impacto-desafios215225149. Acesso em 02 Set 2015. 
Implementacao das obrigacoes, standards e parametros internacionais de direitos humanos no ambito intragovernamental e federativo. Revista Direitos Humanos. n. 01, março, 2008. Recife: GAJOP, 2008.

RAMOS, A. C. Processo internacional de direitos humanos. $2^{\mathrm{a}}$ ed. São Paulo: Editora Saraiva, 2012.

SHAVER, L. The inter-american human rights system: an effective instituition for regional right protetion? (July 22, 2009)Washington University global studies law review 9, 2010. Disponível em http://ssrn.com/abstract=1437633. Acesso em 09 Set 2015.

SORTO, F. O. O uso da força nas relações internacionais: da Paz Perpétua ao Terceiro Ausente. In: TOSI, Giuseppe (org). Norberto Bobbio: democracia, direitos humanos, guerra e paz. João Pessoa: Ed. Universitária da UFPB, 2013.

TRINDADE, A. A. C. El nuevo Reglamento de la Corte Interamericana de Derechos Humanos (2000) y su proyeccion hacia el futuro: La emancipacion del ser humano como sujeto del derecho internacional. In: El Futuro de la Corte Interamericana de Derechos Humanos. San Jose, C.R.: Corte Interamericana de Derechos Humanos, Alto Comisionado de Naciones Unidas para los Refugiados, 2003.

VARELlA, M. D. Direito internacional público. 4 ${ }^{\mathrm{a}}$ ed. São Paulo: Saraiva, 2012.

ZUMBANSEN, P. Comparative, global and transnacional constitucionalismo: the emergence of a transnacional legal-pluralist order. In: Global Constitucionalism. 2012.Disponível em: Acesso em maio 2015. 